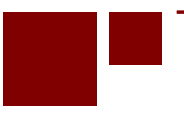

C E N T E R for RETIREMENT RES E A R C H at BOSTON COLLEGE

\title{
EVIDENCE OF INCREASING DIFFERENTIAL MORTALITY: A COMPARISON OF THE HRS AND SIPP
}

\author{
Barry P. Bosworth and Kan Zhang
}

CRR WP 2015-13

July 2015

\author{
Center for Retirement Research at Boston College \\ Hovey House \\ 140 Commonwealth Ave \\ Chestnut Hill, MA 02467 \\ Tel: 617-552-1762 Fax: 617-552-0191 \\ http://crr.bc.edu
}

Both of the authors are with The Brookings Institution. Barry P. Bosworth is the Robert V. Roosa Chair in International Economics and Kan Zhang is a senior research assistant. The research reported herein was performed pursuant to a grant from the U.S. Social Security Administration (SSA) funded as part of the Retirement Research Consortium. The opinions and conclusions expressed are solely those of the authors and do not represent the opinions or policy of SSA, any agency of the federal government, The Brookings Institution, or Boston College. Neither the United States Government nor any agency thereof, nor any of their employees, makes any warranty, express or implied, or assumes any legal liability or responsibility for the accuracy, completeness, or usefulness of the contents of this report. Reference herein to any specific commercial product, process or service by trade name, trademark, manufacturer, or otherwise does not necessarily constitute or imply endorsement, recommendation or favoring by the United States Government or any agency thereof.

(C) 2015, Barry P. Bosworth and Kan Zhang. All rights reserved. Short sections of text, not to exceed two paragraphs, may be quoted without explicit permission provided that full credit, including $\left({ }^{\circ}\right.$ notice, is given to the source. 


\begin{abstract}
About the Center for Retirement Research
The Center for Retirement Research at Boston College, part of a consortium that includes parallel centers at the University of Michigan and the National Bureau of Economic Research, was established in 1998 through a grant from the Social Security Administration. The Center's mission is to produce first-class research and forge a strong link between the academic community and decision-makers in the public and private sectors around an issue of critical importance to the nation's future. To achieve this mission, the Center sponsors a wide variety of research projects, transmits new findings to a broad audience, trains new scholars, and broadens access to valuable data sources.
\end{abstract}

Center for Retirement Research at Boston College

Hovey House

140 Commonwealth Ave

Chestnut Hill, MA 02467

Tel: 617-552-1762 Fax: 617-552-0191

http://crr.bc.edu

Affiliated Institutions:

The Brookings Institution

Massachusetts Institute of Technology

Syracuse University

Urban Institute 


\begin{abstract}
This paper uses data from the Survey of Income and Program Participation (SIPP) and the Health and Retirement Study (HRS) to explore the extent of a widening in life expectancies by socioeconomic status (SES) for older persons. We construct four alternative measures of SES, using educational attainment, average (career) earnings in the prime working ages of 41-50, wealth, and occupational classifications.
\end{abstract}

The paper finds that:

- There is strong statistical evidence in both the SIPP and HRS of a growing inequality of mortality risk by SES across birth cohorts from 1910 to 1961.

- Growing inequality in mortality risk is evident using all four indicators of SES, but it is strongest for the measures based on career earnings and educational attainment.

- The secular changes in differential mortality are very large, but their influence on the length of time for which people receive benefits has been dampened by legal restrictions on early retirement for low-SES individuals and by voluntary postponement of retirement at the top of the distribution.

- Self-reported health status is a highly significant predictor of mortality risk, but its inclusion in the statistical models has only a marginal effect on the evidence of differential mortality operating through the various SES indicators.

- The combination of survey measures of the various SES indicators and the administrative records covering earnings, death records, and OASDI benefits provides a particularly large and rich data set for the analysis of mortality experience and its implications for the distribution of benefits.

The policy implications of the findings are:

- Indexing the retirement age to increases in average life expectancy to stabilize OASDI finances may have substantial unintended distributional consequences, because most mortality gains have been concentrated among workers with relatively high SES. 


\section{Introduction}

The basic structure of the U.S. public retirement system is highly progressive in redistributing income from high-income workers to lower-income retirees. However, it has long been recognized that a large portion of the redistribution is negated on a lifetime basis by the fact that lower-income retirees have a shorter life expectancy and may collect benefits for an abbreviated period of time. ${ }^{1}$ The issue takes on added importance today because of proposals to raise the retirement age in line with increased average life expectancy as a primary means of controlling the system's costs. However, if life expectancy is increasing only for those at the top of the income distribution, an increase in the retirement age seems unfair to lower-income groups with unchanged or even reduced life expectancy.

A large empirical literature has firmly established that life expectancy is strongly correlated with a range of different measures of socioeconomic status (SES), such as income, education, wealth, and occupation. More recent studies also show that the differential in mortality rates across those SES groups has widened in the United States and most high-income countries since the mid- $20^{\text {th }}$ century, reversing a long trend toward greater equality (Waldron 2007). However, there are concerns about some of the indicators of SES that have been used in those mortality studies. This is particularly true for those concurrent measures of SES that might be susceptible to a reverse correlation with health, which is itself a direct determinant of mortality. But questions have also been raised about the robustness of other indicators of SES, particularly in comparisons that extend over long time periods during which the distribution of an indicator may have changed. While we have many surveys with indicators of SES, it is only now becoming common to link those surveys to subsequent death records.

The purpose of this study is to explore the increase in differential mortality among the aged population and its impact on the progressivity of the retirement system by analyzing and comparing data from two surveys, the Survey of Income and Program Participation (SIPP), and the Health and Retirement Study (HRS). ${ }^{2}$ Both of these surveys contain a wealth of SES

\footnotetext{
${ }^{1}$ Changing views of the effect of mortality differences on the progressivity of Social Security are illustrated in the chain of articles from Friedman 1972, Aaron 1977, Smith et al. 2003, and Congressional Budget Office (CBO) 2006. Most of that debate has centered around the retired-worker benefit, but as emphasized in the CBO report, most of the lifetime progressivity flows from the disability and survivor portions of the program.

${ }^{2}$ This paper is an expansion and revision of an early draft (Bosworth and Burke 2014) that was limited to data from the HRS alone. The SIPP is a much larger sample with greater coverage of earnings records from the U.S. Social Security Administration (SSA). We have benefited greatly from access to the administrative data through the Office of Research, Evaluation, and Statistics of the SSA.
} 
indicators and both have ongoing links to Social Security earnings, benefits, and death records. The HRS is limited to individuals in the noninstitutional population over the age of 50; and, while the SIPP surveys the full population, we have also confined the analysis from that source to those over age 50 . The focus on the population over age 50 abstracts from issues, such as the incidence of perinatal deaths, accidents, and homicides, that complicate the interpretation of whole life measures. Nearly 95 percent of Americans will live to age 50, and life after age 50 is more reflective of adult life determinants of SES and the cumulative effects of prior behavioral choices.

A primary objective here is to use information from the two surveys to compare the utility of the major alternative measures of SES-education, income, occupation and wealth-in the prediction of mortality risks for aged persons in the United States. The evaluation of the alternatives will provide evidence with regard to the robustness of the finding of increasing disparities in life expectancy. Most U.S. mortality studies have used educational attainment as the measure of SES, because of its availability as an element of state death certificates and its near universal inclusion in SES surveys. However, education is not a very useful measure for purposes of exploring alternative structures of a retirement system based on individuals’ earnings, and questions have been raised about the interpretation of differences in educational attainment over long periods of time (Bound and others, 2014). With access to the earnings records, it is possible to construct estimates of average or career earnings that reduce the problem of volatility in the more standard survey measure of current income, a primary complaint about its use as an SES indicator. Studies in other countries often use occupation as an indicator of SES, but examples of its use in the United States are uncommon. Both surveys also provide estimates of household wealth, which some researchers prefer as a measure of accumulated lifetime resources. Finally, the surveys include self-reported measures of health status that can be used to explore the potential for reverse causation in the use of income and wealth as indicators of mortality risk. We can also observe the extent to which an intermediate measure of health status substitutes for the correlation between the SES indicator and mortality.

Finally, we analyze the distribution of retirement benefits and show how that distribution is influenced by changing patterns of life expectancy. The changes in the distribution of benefits implied by changing patterns of differential mortality are compared on the basis of the analysis of differential mortality in the SIPP and HRS. 


\section{Prior Research}

Following the path-breaking work by Kitagawa and Hauser (1973), there has been an explosion of epidemiological research on the link between mortality and different measures of SES. The early research was limited by difficulties of combining detailed mortality data with comprehensive measures of SES. Kitagawa and Hauser combined information from the long form of the 1960 census with a national sample of death records. Research of this type has been greatly accelerated by the creation of a national death index and computer-assisted searches of linked data sets. The U.S. research has been particularly extensive, because death certificates often contain information on educational attainment. Reviews of the older research studies are available in Feinstein (1993) and Wilmoth and Dennis (2007). Preston and Elo (1995) reviewed a number of those studies and reported a mixed story in which the mortality differential had clearly widened since 1960 for males, but it appeared to have declined or remained stationary for women.

More recently, Meara, Richards and Cutler (2008) and Olshansky et al. (2012) analyzed death certificate data, using educational attainment as a measure of status, and found evidence of a rapidly rising mortality differential between 1981 and 1998. Waldron (2007, 2013) used administrative records containing information on career earnings (average of ages 45-55) and age at death to establish a similar pattern for men covered by Social Security. In her 2013 paper, Waldron expanded her analysis to estimate mortality risk as a more detailed relationship with male workers' positions in the earnings distribution (deciles). She used that analysis to argue against any notion of a threshold effect of career earnings on mortality risks, favoring a continuous gradient model of risk. Singh and Siahpush (2006) provided additional evidence of changes in the degree of differential mortality using county-level information from the decennial censuses. Cristia (2009) used career earnings from Social Security records as the indicator of SES and reported substantial increases in differential mortality for 1983-2003.

Research in other countries demonstrates that increasing differential mortality is an international phenomenon with a range of interesting results. The National Research Council (2010) provides a detailed review of mortality differences among those over age 50 within a sample of high-income countries. In Britain, the first Whitehall study of male employees in the British civil service, initiated in 1967, documented a steep inverse relationship between civil service grade and health and mortality outcomes. Men in the lowest grade had a mortality risk 
three times higher than that of those in the highest grade. The study was particularly important because in focusing on civil servants it largely excluded those who would be classified as poor, demonstrating that premature mortality was not limited to the poor and near poor, and that the relationship between mortality and an index of SES was best described as a continuous gradient. It was also one of the first studies to show that only a small proportion of the difference in outcomes could be traced to behavioral risks or lack of access to care.

It is common to argue that measures of SES are reflective of cumulative long-term intractable influences on mortality; yet the experience of East Germany after unification suggests the opposite, because life expectancy at age 65 improved dramatically after 1990 and converged to that of West Germany by the mid-2000s. Meanwhile, other East European countries continued to lag behind. The convergence of old-age life expectancy in Germany is attributed to large increases in old-age pensions and the expansion of access to health care in the East (Vogt and Kluge 2014). At the same time, the convergence across the two regions has been accompanied by increased differential mortality across SES groups when measured by relative pension amounts (a proxy for work-life income) and occupation (Kibele and others 2013). Those with the highest SES in East Germany showed the largest improvements in mortality.

Canada provides a useful comparison to the United States because, while it shares some similarities in its measures of SES, it has long provided an advanced national health care system open to all. A data base links SES information from the Census long form with the administrative records of 2.7 million individuals, who were followed from 1991 to 2001 with a total of about 260,000 deaths. The analysis of that data (Wilkins et al. 2008) revealed a strong inverse correlation between mortality risk and a variety of SES indicators, such as education, occupation and family income. Another study used administrative data from the Canadian pension system to examine the relationship between a measure of career earnings and mortality at ages 65-74 (Wolfson and others 1993). It also found a strong negative relationship with mortality throughout the earnings distribution. However, very little research is available on the question of whether the magnitude of differential mortality is increasing over time.

\section{Basic Data Sources}

The SIPP began in 1984, and we have combined data from the 1984, 1993, 1996, 2001, and 2004 panels for individuals born between 1910 and 1961. The HRS started in 1992 with the 
original sample of individuals born between 1931 and 1941. But it was supplemented in 1993 with a sample of individuals born before 1924, and in 1998 with samples of those born in 192430 and 1943-47. Younger cohorts have continued to be brought into the study every six years. We have included individual born between 1910 and 1957. ${ }^{3}$ Both surveys are linked to Social Security records on work-life earnings, benefits, and deaths.

Within the SIPP, we were able to successfully match about 80 percent of the respondents to their corresponding Social Security earnings and death records. ${ }^{4}$ As discussed later, the sample was further limited to members of households with nonzero earnings for ages 41-50. The result is a total sample of 65,000 men and 72,000 women (see the top panel in Table 1). ${ }^{5}$ Among these, about 100,000 respondents were "married, with spouse present" at the time of the SIPP interview. We were able to successfully match slightly less than 98 percent of these married respondents to their spouse's Social Security record. The sample also includes a total of 33,000 deaths. We then created a person-year dataset in which each respondent enters the sample in the year corresponding to their initial SIPP interview (beginning in 1984) and remains in the sample until the year of their death or until 2012 (the last year for which we have reliable death data). That dataset has a maximum of about 740,000 observations for men and 895,000 for women. The SIPP has a short longitudinal structure with 8-12 waves or topical interviews over a span of about four years.

The HRS comprises a considerably smaller data set of 13,000 men and 17,000women, but it has continued to re-interview them on a biennial basis providing updated information on their social, economic, and health situation. However, there have been much greater difficulties in obtaining permissions to use individual administrative records. Thus, members of households with reported earnings records fall to only 60 percent of the initial sample. However, we are not restricted to the SSA administrative records for reported deaths since the HRS maintains its own

\footnotetext{
${ }^{3}$ The terminal birth year of 1957 is dictated by the lack of Social Security earnings data after 2007.

${ }^{4}$ In the early years of the survey, respondents were asked for their Social Security numbers, but the refusal rate rose rapidly in later years, particularly for interviews that relied on a phone contact. Currently, unless respondents specifically opt out, the linkage to their administrative record is based on a probabilistic match.

${ }^{5}$ The sample cannot be viewed as fully representative of the population of persons over age 50. Particularly in the early years of the Social Security system, many employees of governments and non-profits were excluded and would not have earnings records. In the construction of the income indicator, we also required that individuals or their spouses have nonzero earnings for ages 41 to 50. Furthermore, the SIPP samples on which the dataset is built were limited to the non-institutionalized population. Finally, some respondents refused permission to access their Social Security records. However, Cristia (2009) found only small differences between a similar mortality sample and the distribution in the SIPP by age, sex, and race. We do not explore the issue further and assume that the 20 percent of respondents who could not be matched are randomly distributed across the full SIPP sample.
} 
tracker file. The HRS comprises an older group of respondents than the SIPP with a higher overall death rate; but as shown in Table 1, the death rates are quite comparable for the individual birth cohorts.

\section{Alternative Indicators of SES}

Indicators of SES are meant to provide information about an individual's access to social and economic resources. As such, they are often used to indicate position within a hierarchical social structure. We can identify four common indicators of SES that have been linked to health and mortality outcomes: education, income, occupation and wealth. They vary in their availability or relevance as indicators of SES in health and mortality studies. The highly detailed baseline surveys of the SIPP and HRS provide an unusual opportunity to compare the SES indicators and their efficacy as predictors of mortality risks.

Education. In examinations of the link between SES and mortality, most studies have used education because its measurement is easy and practical in survey contexts. Interestingly, it is included as an element of most Americans’ death certificates. Education is normally determined in early adulthood and is therefore least likely to be subject to reverse causation from other determinants of mortality, such as general health status. Both the SIPP and the HRS surveys include questions about educational attainment.

Education as an indicator of SES has some limitations, however. Relative to income, there has been decreasing variability in years of education over recent decades. Also, most studies of SES use an individual's education, and that may miss the role of the educational attainment of other family members (especially that of the spouse) in determining a person's social and economic status. Furthermore, education is not particularly useful as a policy instrument for social programs. For example, the Social Security program determines benefits on the basis of an individual's lifetime earnings, not educational attainment. If there is evidence that mortality differentials are widening and policymakers conclude that a recalibration of the benefit formula is needed to compensate low-income contributors for their relatively small gains in longevity, it is hard to see how measures of widening mortality differentials by educational attainment can be useful in reforming the formula. 
Finally, in a recent critique of the 2012 paper by Olshansky et al., Bound and others (2014) noted that there has been a substantial improvement in average levels of educational attainment over the range of birth cohorts included in our analysis. Thus, it is possible that classifying individuals by completed grade or degree attained does not yield a consistent measure of SES rank across birth cohorts. In our data from the SIPP, we observe an increase in years of schooling between the 1910 and 1947 birth cohorts of about 31/2 years, from about 10 to $13^{1 / 2}$ years. But for the baby boom and later cohorts, educational attainment is constant for women and actually declines slightly for men. We dealt with this problem by converting the education categories to number of years of schooling and indexing the person's years of schooling to an average of the educational attainment of their surrounding birth cohorts (five years). The calculations were done separately for men and women and effectively eliminated any trend in the measure of relative education. ${ }^{6}$

Income. Some of the early studies of mortality used current income, because it was available from Census or other periodic surveys. However, it has long been recognized that it is a poor basic indicator of SES because of its sensitivity to adverse health events or other transitory events. Access to Social Security earnings records makes it possible to use an average of past earnings-what we label as "career earnings"-as an income-based measure of SES, while avoiding many of the problems caused by using current income. A 10-year average of midcareer earnings dilutes the role of transitory influences and comes close to the concept of permanent income. The focus on mid-life income also reduces, though it does not eliminate, the potential for reverse causation flowing from health to income.

However, the nature of the earnings data has changed over the years. Until 1978, SSA maintained its own records based on quarterly reports of employers. In 1978, it switched to a reliance on the annual earnings information available from IRS W-2 forms as part of a program to reduce respondent burden. The 1951-77 earnings data were limited to covered wages up to the taxable wage ceiling, which was a low and varying ratio to the average wage-only 3 percent above the average in 1965 compared to 69 percent in 1977. We have imputed earnings above the taxable wage ceiling using information on the quarter in which the worker exceeded the

\footnotetext{
${ }^{6}$ There is also a change in the SIPP's education question in the 1996 and later surveys. In the 1984 and 1993 surveys, respondents were asked for their highest grade attended and whether they completed that grade. In later years, the questionnaire changed to the highest degree received for those beyond high school.
} 
maximum. That is, for those who reached the ceiling with four quarters of reported earnings, the annual estimate was set to 1.14 times the taxable maximum, those with three quarters were assigned 1.53, two quarters to 2.36, and those who reached the ceiling in the first quarter were set at 5 times the taxable maximum. ${ }^{7}$ The $\mathrm{W}-2$ data, in use since 1977, have the major advantages of providing measures of earnings in excess of the taxable wage ceiling and including earnings from both Social Security-covered and uncovered jobs. The annual earnings were capped at the $98^{\text {th }}$ percentile to reduce the impact of a few very large values in the post-1977 data. $^{8}$

A measure of average or career earnings was created by first deflating the nominal annual earnings by the SSA average wage index with a base of 2005, thereby eliminating the influence of secular wage growth. Career earnings were computed as an average of real nonzero earnings over the age range of 41-50. ${ }^{9}$ The resulting average values are shown separately for men and women by birth year in Figure 1, and they raise some of the same issues as for the education indicators. Because women were increasingly likely to be in the labor force, their measure of career earnings is steadily rising relative to that of men. Meanwhile, the average wage of men is declining for the younger birth cohorts. Furthermore, the overall wage index includes the earnings of all workers in a given calendar year, rather than only those at ages 41 to 50, so career earnings will be influenced by changes in the age distribution of the overall labor force. To eliminate the secular drift, we employed an adjustment similar to that used to convert to a relative measure of education: individual career earnings were indexed by the career earnings of the five surrounding birth cohorts. The calculations were done separately for men and women.

A final complication involves the treatment of married individuals. Work histories of older married women up through the 1940s birth cohorts were limited, making career earnings a

\footnotetext{
${ }^{7}$ The adjustment ratios were originally derived for a report to SSA, Toder et al. (1999). Class intervals were set under an assumption of steady earnings throughout the year, and the class means were derived from the distribution of wages in various reports of the Current Population Survey. Less than 1 percent of the workers in the sample reached the taxable maximum in the first quarter. A similar methodology was also used more recently in Cristia (2009) and Kopczuk, Saez, and Song (2010). Additional problems with the changeover to W-2 records in 1978-80 led us to use an interpolation of individuals' earnings above the taxable ceiling between 1977 and 1981 . No adjustment could be made for the self-employed who were above the taxable wage ceiling as they file on an annual basis.

${ }^{8}$ Even after our adjustments, the pre-1977 data are not fully compatible with the later years because of considerable clumping after adjusting for the quarter in which individuals reach the taxable wage ceiling.

${ }^{9}$ The computation of career earnings is adapted from Waldron (2007). As she noted, the reliance on years with nonzero earnings does exclude some low-wage workers with poor health and likely leads to an understatement of the mortality risk for the disabled and workers near the bottom of the income distribution.
} 
particularly problematic indicator of their SES. Therefore, we rely on a construct that combines husband and wife earnings as the primary income-based measure of household-level SES. We define household earnings for individuals with a spouse as the sum of the two career earnings divided by the square root of two. For those without a spouse, we use individual career earnings. That does result in the exclusion from the analysis of individuals who were single in the SIPP and did not have positive earnings between ages 41 to 50 .

The HRS has matching Social Security records for a smaller percentage of the participants than for the SIPP, and there were additional problems with the records for those who entered the study in its initial years. ${ }^{10}$ As a result, the proportion of the sample with career earnings falls to below 50 percent (Table 1). ${ }^{11}$ To extend the analysis beyond those with an earnings record to the full sample, we estimated relationships for male and female career earnings that include a wider range of variables from the survey (Appendix Table A1). We use the regressions shown in columns 2 and 4 of that table to generate predicted values for the full sample, thereby obtaining a measure of individual and household earnings for nearly everyone. While we report some of the mortality results based on the restricted sample with non-missing earnings, we also used the predicted values as our income-based indicator.

Wealth. Wealth provides individuals with the resources to meet emergencies, absorb economic shocks, and obtain superior health care. It is also a summary measure of lifetime income in cases where a direct measure of income is unavailable. As such, it ought to be a powerful indicator of SES. Attanasio and Hoynes (2000) employed data from the SIPP to measure the relationship between wealth and mortality. They reported a large inverse relationship between individuals' relative positions in the wealth distribution and mortality risk. However, their analysis did not utilize information from the SSA records, and the observation on deaths is thus limited to 21/2 year observation periods from the 1984 and 1987 panels. The short period of time between the observation on wealth and possible deaths heightens the concern, as with measures of current income, about the potential for a reverse correlation with poor health

\footnotetext{
${ }^{10}$ For some members of the original HRS and the older members in the AHEAD sample, we are unable to adjust earrings above the taxable maximum due to missing information regarding the quarter in which earners reached the taxable maximum. This problem should be fixed in the next update of the administrative records.

${ }^{11}$ In addition, details of the post-1977 earnings are suppressed at the top by restricting values to a range of $\$ 250,000-\$ 300,000, \$ 300,000-\$ 500,000$, and $\$ 500,000$. We replaced those ranges with, $\$ 275,000400,000$ and 500,000 , respectively.
} 
resulting in declines in wealth. We try to reduce this problem by focusing on measures of wealth in the earliest possible wave of each survey and extending the observations on mortality to 2012.

Both the SIPP and the HRS provide estimates of overall wealth defined as total asset less total liabilities. They include owning a home and vehicles among nonfinancial assets and deduct consumer debt. The wealth numbers are deflated by the CPI-U-RS for the survey year and negative values are set to zero. For the HRS, the wealth is drawn from the earliest possible wave of each respondent, and we have wealth estimates for the entire sample. Wealth estimates were available for 92-94 percent of individual in the SIPP.

Occupation. Occupational status is often used, because of the difficulty of obtaining information on long-term earnings, and also because it helps to define characteristics of employment that are relevant to measuring health risks, lifestyle behaviors, and access to healthrelated resources. It has been a more common element of mortality studies in Europe than in the United States. The basic problem is that there is no natural ranking of occupation that can easily convert into an index of SES. We did experiment with a nine-category classification for the HRS based on the occupation of the longest duration, and those results are reported in a later section. The occupational measure was missing for about 6 percent of the male population and 20 percent of the female population. We were unable to obtain a consistent indicator of occupation from the SIPP.

Other Variables. Our analysis deals separately with mortality risks of men and women, but, in addition to the SES indicators, we include categorical variables measuring race/ethnicity and marital status. Both surveys also include a self-reported measure of health status, which is of interest because it identifies one channel by which variations in SES might influence mortality. For the SIPP, we have a single measure from the individual's entry panel. That value can range from a value of 1 for those in excellent health to 5 for those in poor health. The same measure is available in the HRS, but it is reassessed in each biennial wave. We used the reported value from each person's entry interview. We also experimented with an indicator from the HRS of whether or not the respondent has ever received disability benefits. The measure is not available from the SIPP. 


\section{Estimation of Mortality Risks}

We constructed an annual data file in which each respondent is included beginning from the year of entry into the sample or in the year in which they reach age 50, and they remain in the data set through the year $2012^{12}$ (the last year of reliable death information) or their year of death. For the SIPP, the file includes individuals with the birth years 1910 to 2011, and the earliest entry year is 1984 and the latest is 2004 . The result is a data set with 740,000 observations for men and 895,000 for women. For the HRS, the file includes individuals with the birth years 1910 to 1957, and the earliest entry year is 1992 and the latest is 2004 (early boomers). There is a maximum of 162,000 observations for men and 216,000 for women.

The statistical analysis is based on a proportional hazard model of mortality risk that takes the form:

$$
\text { (1) } \operatorname{mortality}(X)=\exp \left(\beta_{i} * X_{i}\right) \text {, }
$$

where $X$ is a vector of potential determinants of mortality risk. As potential determinants, the regressions include the person's age, birth year, and categorical variables for race/ethnicity and marital status. ${ }^{13}$ Ages range from 50 to 100 , and birth year begins at zero in 1900 . We experimented with alternative nonlinear measures of age, but they were not statistically significant. The birth year is our basic indicator of cohort effects. Most importantly, there are four alternative indicators of SES with which to measure differential mortality - and for each measure we include the interaction of SES with the birth year to measure increasing or decreasing magnitudes of differential mortality. We also experimented with measures of health status as well as with whether the respondent had received disability (HRS only) to observe their impact on the measured magnitude of differential mortality.

Some preliminary results using the SIPP data are shown in Table 2. Mortality risks for men and women are estimated separately, and the table includes all of the basic determinants but excludes any interaction with birth year. There is a strong age profile for both men and women, and a negative cohort effect for men-a trend of declining mortality-but the coefficient is slightly

\footnotetext{
${ }^{12}$ For the HRS, the death data became unreliable beginning in year 2011, limiting our analysis to calendar year 2010.

${ }^{13}$ We included a categorical variable for the first calendar year of their enrollment as recognition that respondents are exposed to the risk of dying for less than a full 12 months.
} 
positive for women. Despite the correlation among them, all three measures of SES have a significant negative relationship with mortality. Race and marital status are highly significant discriminators of mortality risk. Self-reported health status is also strongly correlated with mortality risk; yet, its inclusion does not eliminate the role for the SES indicators.

A more detailed presentation that focuses on the alternative measures of SES individually and introduces a test for differential mortality is shown in Table 3. Again, mortality risks for men and women are estimated separately, and each column represents a different formulation of the SES indicator (household career earnings, educational attainment and wealth). In part because of the sample size, everything has high statistical significance. Surprisingly, there is very little to choose from among the three indicators of SES: they all show very significant negative coefficients on the interaction of the SES indicator with the birth year, implying strongly increasing differential mortality. The measures of overall explanatory power are virtually identical. For the regressions based on education and income, it is possible to include the other as a second measure, suggesting that the best single SES indicator might be a combination of education and career earnings. The interpretation of the coefficients on the birth year and SES variables are complicated in the presence of the interaction term. For both career earnings and education, the coefficients on the SES term and the birth year individually are positive but the interaction term is negative. However, the net effect of career earnings is negative and growing for men born after 1915, and after 1912 for education. The interaction of education with birth year also has a larger negative coefficient than the interaction of career earnings with birth year, suggesting a more pronounced pattern of increasing differential mortality. However, the larger coefficient can be traced to the limited variance in educational attainment compared to career earnings.

The comparison of the estimates for men and women indicate extremely similar coefficients for many of the determinants of mortality. As with men, there is strong evidence of increasing differential mortality when using either career earnings or educational attainment. However, there is no evidence of increasing differential mortality in wealth for women. It is also noteworthy that marital status has a much smaller effect on female mortality: apparently women are more capable of taking care of themselves.

Comparable results for the HRS are displayed in Tables $4 \mathrm{a}$ and $4 \mathrm{~b}$. The construction of the household earnings variable results in a considerable loss of observations; so Table 4a also 
includes a regression using predicted earnings as an additional indicator of SES. As with the SIPP, the results indicate strongly increasing differential mortality, although its magnitude is small in the regression for males using actual household earnings. The regressions using educational attainment are very similar to those for the SIPP, with the coefficient on the interaction with birth year being negative and highly significant. Wealth performs better as an indicator of SES in the HRS, perhaps because the measure appears to be of higher quality in the HRS (Czajka and others 2004).

Table 4a shows the results of using nine summary categories of occupational codes as the SES indicator. Overall, the set of codes have high statistical significance-equal to or better than the other SES measures. However, the coefficients on individual occupations are difficult to interpret in any simple scale, and they vary substantially between men and women. The effort to measure changing patterns of differential mortality by including an interaction of each occupational category with birth year is generally unsatisfactory. Those coefficients also vary both in sign and statistical significance, often having an unexpected positive association. We conclude that, while occupational codes do reflect many of the characteristics of other SES indicators, the lack of a straightforward quantitative scale limits their usefulness. Judging by the overall fit of the equations, the occupational indicator does not provide significant additional information about mortality risk beyond that of the other SES indicators.

Furthermore, there is a question about the extent to which health defines the channel through which SES influences mortality. Thus, for the set of regressions shown in Tables 3 and 4, we estimated an alternative with the addition of self-reported health status. In all cases, health status had high statistical significance, but it had a relatively small effect in reducing the size of the coefficient on the interaction term between the SES indicator and birth year-our measure of increasing differential mortality. For the SIPP, the coefficient on the interaction of education and birth year was cut by 5 percent for men and 15 percent for women. The reduction for career earnings was 10 percent for men and 15 percent for women. In the HRS, the reduction for the education interaction was larger — 25 percent for both men and women - and the change for career earnings varied between 30 percent for men and 10 percent for women. Overall, we interpret the result as an indication that the finding of a consistent pattern of increasing differential mortality is operating through channels in addition to health status. Finally, the HRS also asks if the respondent has ever received disability benefits. In all of the estimates, disability 
has a very large and significant positive impact on mortality risk, but again without reducing the role of the SES interactions with birth year.

\section{Implications for the Distribution of Retirement Benefits}

It has long been recognized that differences in life expectancy offset a significant portion of the progressivity of the Old Age Survivors and Disability Insurance (OASDI) system when benefits are measured on a lifetime basis. The objective of this portion our analysis is to measure the distribution of retirement benefits relative to that of career earnings and then to use the results from our mortality analysis to compute expected lifetime benefits and their distribution.

Within our sample of SIPP respondents, we rely on the measure of money benefits reported on their OASDI benefit records. Again, we restricted the sample to those with birth years between 1910 and 1961. For men, 42,000, or 61 percent of the sample of those over age 50, received a benefit at some time before 2012. Similarly for women, there are 52,000 beneficiaries, or 66 percent of the sample receiving benefits. Benefits are initially defined at the individual level and include retirement, disability and survivor benefits after deduction of any Part B (supplementary medical insurance) premiums. They are converted to 2005 dollars using the CPI-U-RS price index. Thus, absent changes in classification (disabled, retiree, spousal or survivor beneficiaries), we expect the benefit value to be relatively constant over time. Those real values are averaged across the years for which they were reported beginning at age 50 and up to the year 2012.

For the HRS sample, benefit values are those reported by recipients in the biennial interview. We use the self-reported values because we have OASDI benefit records for less than half the sample. ${ }^{14}$ The number of male beneficiaries is about 10,000 (75 percent of those over age 50) men, and the number of women is about 13,000 (79 percent of the total).

We made a final adjustment for individuals with a spouse: the two benefits, as with earnings, are summed and divided by the square root of 2 . The household-equivalized benefits are significantly higher and more widely distributed than the individual measure for women, but the adjustment has less effect on the distribution of men's benefits. We believe that the

\footnotetext{
${ }^{14}$ We did compare the administrative and self-reported values. The simple correlation between the two series is 0.83 , the self-reported values were 6 percent higher than the administrative measure, and the variances differ by less than three percent.
} 
equivalized measure is a more accurate reflection of individuals' economic condition during their retirement years. $^{15}$

We use the mortality equations in Tables 3 and 4 to compute expected life expectancy as the sum of the survival probability $\left(S_{x}\right.$ for each individual over the age range of 50 to 99 as

$$
S_{x}=S_{x-1} *\left(1-D_{x}\right)
$$

where $D_{x}$ is the expected conditional death rate at each age. Expected benefit years were computed with the same formula, but beginning with the age of first receipt of benefits. Lifetime benefits are the expected benefit years times the individual's fixed benefit. ${ }^{16}$ As with the mortality equations, the analysis differentiates between men and women, and we have several sets of lifetime benefits using different mortality regressions, primarily using education and career earnings as a measure of SES. We have not incorporated any discounting of future benefits in order to focus on the role of differences in expected mortality.

The distributions are constructed by ranking each individual by the decile of their equivalized career earnings, and computing for each decile the mean of career earnings, point-intime (annual) equivalized benefits, and lifetime benefits. We computed the distribution on the basis of both individual and equivalized career earnings but report only those for the equivalized measure.

The basic results are reported in Table 5 and summarized in Figure 2. The distributional aspects are highlighted by showing career earnings, point-in-time benefits, and lifetime benefits in each earnings decile as a percentage of their own mean value. Thus, at the top of Table 5, the results for the SIPP sample show equivalized career earnings for men rising from 17 percent of the mean in the lowest decile to 233 percent in the top decile. The distribution of equivalized earnings is actually slightly wider for women. In addition, there is a considerable compression of annual benefits, and the decile averages range for men from 57 percent of the mean in the lowest decile to 129 percent at the top. The range for women is from 63 to 138 percent of the mean.

\footnotetext{
${ }^{15}$ For the lower-earning spouse, equivalized earnings are closer to their economic status both before and after the death of their partner.

${ }^{16}$ For those individuals who began receiving benefits before age 50, we calculate benefit years beginning at age 50 . In a few cases, we do not know the date that benefits began and assume age 62.
} 
We also report their life expectancy at age 50 and the number of years they can expect to receive benefits. There is a substantial variation of life expectancy for men, ranging from 25 years in the lowest earnings decile to 41 years at the top-a 16-year difference. The divergence is less for women, as their advantage over men narrows considerably in the transition from low to high equivalized earnings. The distribution of expected benefit years is narrower than that for life expectancy, because individuals in lower income classes are constrained by the minimum retirement age and those at the top of the distribution often voluntarily delay retirement to a later age. The differences in expected benefit years widen the distribution of lifetime benefits relative to annual benefits, and the result is about halfway between that of career earnings and that of annual benefits, but most of the change is at the top of the distribution. In the bottom decile, the measure of lifetime benefits is reduced by 10 percent relative to annual benefits and it is increased by 22 percent at the top. The patterns of change in the distributions are more evident in the top panel of Figure 2, which shows the patterns of annual and lifetime benefits relative to that of career earnings for men (left panel) and women (right panel). Benefits are still more uniformly distributed on a lifetime basis than career earnings, but the differential mortality does offset a significant portion of the progressivity built into the point-in-time benefit formula.

The middle and bottom panels of Table 5 present similar calculations based on the actual and predicted earnings of the HRS. The results for the panel using actual earnings are virtually identical to the SIPP, but the estimate of the change across the income deciles of life expectancy at age 50 is notably less than in the SIPP. The increase in life expectancy between the $1^{\text {st }}$ and $10^{\text {th }}$ deciles is 10 years in the HRS versus 16 in the SIPP. Still, the comparison of lifetime to annual benefits is very similar in the HRS and SIPP (lower and upper panels of Figure 2). The distribution of predicted earnings is much more uniform than that for actual earnings, because we cannot account in the earnings regressions for the extremes of very low and very high earnings. The more uniform distribution of earnings carries over to a slightly more compressed distribution of annual and lifetime benefits, but the extent of change in the comparison of annual and lifetime benefits is small. In the bottom decile, the measure of lifetime benefits is reduced by 18 percent relative to annual benefits and is increased by 11 percent at the top.

We can further highlight the role of increasing differential mortality by re-computing the probability of survival under two extreme assumptions where all individuals are born in either 1920 or 1940. We performed the calculation using the mortality equations shown in Table 3 
(SIPP) and Table 4 (HRS) where changes in differential mortality are measured by the interaction of career earnings and birth year. ${ }^{17}$ Thus, the distribution of career earnings and annual benefits remain unaffected, but life expectancy and lifetime benefits change for those born in 1940 relative to those with a birth year of 1920 .

Life expectancy at age 50 and expected years of benefits for the two birth cohorts, distributed by deciles of career earnings, are shown in Table 6. To highlight the changes by birth year, we show the values for both the 1920 and 1940 birth cohorts as a percent of the mean benefit in 1920. Using the results from the SIPP, life expectancy at age 50 for men is projected to rise from 26 to 31 years, and the number of benefit years is projected to rise from 17.4 to 21.3 years between the 1920 and 1940 birth cohorts. That translates into a 22 percent increase in the average lifetime benefit, but the distribution is very skewed, because the number of benefit years rises by only 0.5 years in the lowest decile and by 8.5 years in the $10^{\text {th }}$ decile. The influence of this increase in differential mortality is more evident in the top panel of Figure 3, which shows the widening gap in lifetime benefits between the two birth cohorts at higher deciles of the earnings distribution. The gain in the lowest decile is only 3 percent, but near 50 percent in the $10^{\text {th }}$ decile. For women, the increase in life expectancy and benefit years is much smaller than for men, although the levels remain higher. The average increase in benefit years is only two years and it is expected to decline for the lowest two quintiles of the earnings distribution, but it increases by six years in the top decile. As a result, there is a large rotation of the distribution of lifetime benefits for women. The average benefit increases by only 11 percent, but the gain is 25 percent in the $10^{\text {th }}$ quintile and the loss is 4 percent in the $1^{\text {st }}$ quintile.

Using the results from the HRS, the average life expectancy at age 50 for men is projected to rise from 28 years for the 1920 birth cohort to 30 years for those born in 1940, and the average number of benefit years increases from 18 to 19.6 years. That is only about half of the magnitude of the increases estimated from the SIPP data. In addition, the HRS implies a more uniform change across the various quintiles of male career earnings. The increase in benefit years is 0.6 years in the lowest quintile and 2.9 years at the top. In effect, it indicates a smaller degree of increase in differential mortality for men. For men, the gain in benefits is about 4 percent in the bottom decile and 14 percent at the top (bottom panel of figure 3)-

\footnotetext{
${ }^{17}$ We limited the analysis to the mortality equations based on career earnings, but the results based on education and wealth are not qualitatively different. In effect, all of the right-hand side variables other than birth year remain unchanged across the two birth cohorts.
} 
significantly less than the 50 percent computed from the SIPP. The average gains for women are also smaller in the HRS than in the SIPP; but there is still a substantial change across the earnings quintiles with a drop in the number of years for receiving benefits in the lowest four quintiles and an increase at the top. Thus, lifetime benefits for those 1940 birth cohort compared to those born in 1920 fall by about 10 percent in the first decile and rise by 20 percent at the top.

\section{Conclusions}

The first major conclusion of this study is that a wide range of SES indicators, including career earnings, education, wealth and occupation all seem to work surprisingly well in accounting for differences in mortality risks. However, the results are most robust for career earnings and educational attainment. Second, except for the occupation indicator, the various indicators of SES were highly consistent in finding strong statistical evidence of increasing differential mortality in data samples constructed from both the SIPP and the HRS. We also find that self-reported health status is a highly significant predictor of mortality risk, but its inclusion in the statistical models has only a marginal effect on the evidence of differential mortality operating through the various SES indicators.

The secular changes in differential mortality are very large, but their influence on the length of time for which people receive benefits has been dampened by legal restrictions on early retirement for low-SES individuals and by voluntary postponement of retirement at the top of the distribution. We find that differences in mortality across the earnings distribution offset some of the progressivity built into the retirement benefit program, but the resulting pattern of benefits remains progressive.

We believe that these findings about the pervasiveness of a pattern of increasing differential mortality have important implications for policy. The findings suggest that the current emphasis on increasing the retirement age in line with increases in average life expectancy may have substantial unintended distributional consequences. That is because most mortality gains have been concentrated among workers with relatively high SES.

Finally, we found that the combination of survey and administrative data in the SIPP yields a very large data file for analysis of the link between various socioeconomic indicators and the pattern of retirement benefits. In contrast, the HRS is handicapped by the incomplete nature of the administrative records. 


\section{References}

Aaron, Henry. 1982. Economic Effects of Social Security. Brookings Institution: Washington, DC.

Attanasio, Orazio and Hilary Williamson Hoynes. 2000. "Differential Mortality and Wealth Accumulation.” The Journal of Human Resources 35(1): 1-29.

Bosworth, Barry and Kathleen Burke. 2014. "Differential Mortality and Retirement Benefits in the Health and Retirement Study.” Working Paper 2014-4. Chestnut Hill, MA: Center for Retirement Research at Boston College.

Congressional Budget Office. 2006. Is Social Security Progressive. Economic and Budget Issue Brief. Washington, DC.

Cristia, Julian. 2009. "Rising Mortality and Life Expectancy Differentials by Lifetime Earnings in the United States.” The Journal of Health Economics 28: 984-995.

Czajka, John, Jonathan E. Jacobson, and Scott Cody. 2004. "Survey Estimates of Wealth: A Comparative Analysis and Review of the Survey of Income and Program Participation." Social Security Bulletin 65(1): 63-69.

Friedman, M. 1972. “Second Lecture,” in W. Cohen and M. Friedman, Social Security: Universal or Selective? Washington, DC: American Enterprise Institute.

Kibele, Eva, Domantas Jasilionis, and Vladimir Shkolnikov. 2013. "Widening Socioeconomic Mortality Gradient in Germany and Its Implication for the Closing East-West Mortality Gap.” Journal of Epidemiology and Community Health 67(5): 453-57.

Kitagawa, Evelyn M and Philip M Hauser. 1973. Differential Mortality in the United States: A Study in Socioeconomic Epidemiology. Vol. 35. Cambridge, MA: Harvard University Press.

Kopczuk Wojciech, Emmanuel Saez, and Jae Song. 2010. “Earnings Inequality and Mobility in the United States: Evidence from Social Security Data since 1983.” The Quarterly Journal of Economics 125(1): 91-128.

Marmot, Michael and M.E. McDowall. 1986. "Mortality Decline and Widening Social Inequalities.” Lancet 328: 274-76.

Meara, Ellen, Seth Richards, and David M. Cutler. 2008 "The Gap Gets Bigger: Changes in Mortality and Life Expectancy, by Education, 1981-2000.” Health Affairs 27(2): 350360. 
National Research Council. 2010. "International Differences in Mortality at Older Ages: Dimensions and Sources.” In Panel on Understanding Divergent Trends in Longevity in High-Income Countries. Committee on Population, Division of Behavioral and Social Sciences and Education, edited by Eileen M. Crimmins, Samuel H. Preston, and Barney Cohen. Washington, DC: The National Academies Press.

Olshansky, S. Jay, Toni Antonucci, Lisa Berkman, Robert H. Binstock, Axel Boersch-Supan, John T. Cacioppo, Bruce A. Carnes, Laura L. Carstensen, Linda P. Fried, Dana P. Goldman, James Jackson, Martin Kohli, John Rother, Yuhui Zheng, and John Rowe. 2012. "Differences in Life Expectancy due to Race and Educational Differences Are Widening, and Many May Not Catch Up.” Health Affairs 31 (8): 1803-13.

Preston, Samuel and Irma Elo. 1995. “Are Educational Differentials in Adult Mortality Increasing in the United States?” Journal of Aging and Health 7: 476-96.

Singh, Gopal K. and Mohammad Siahpush. 2006. "Widening Socioeconomic Inequalities in U.S. Life Expectancy, 1980-2000.” International Journal of Epidemiology 35: 969-979.

Smith, Karen, Eric Toder, and Howard Iams. 2003. "Lifetime Distributional Effects of Social Security Retirement Benefits.” Social Security Bulletin 65(1): 33-61.

Social Security Administration. 2013. Annual Statistical Supplement to the Social Security Bulletin, 2012. Table 5.A14. Washington, DC.

Steuerle, Eugene, Lee Cohen, and Adam Carraso. 2004. "How Progressive Is Social Security and Why?” Straight Talk on Social Security and Retirement Policy Brief 37. Washington, DC: The Urban Institute.

2004. "How Progressive Is Social Security When Old Age and Disability Insurance Are Treated as a Whole?” Straight Talk on Social Security and Retirement Policy Brief 38. Washington, DC: The Urban Institute.

Toder, Eric, Cori E. Uccello, John O’Hare, Melissa M. Favreault, Caroline Ratcliffe, and Karen E. Smith. 1999. Modeling Income in the Near Term Projections of Retirement Income Through 2020 for the 1931-60 Birth Cohorts. Washington, D.C.: Urban Institute.

Vallin J, Meslé F. and Valkonen T. 2001. Trends in Mortality and Differential Mortality. Strasbourg, FR: Council of Europe Publishing.

Vogt, Tobias and Fanny Kluge. 2014. “Can Public Spending Reduce Mortality Disparities? Findings from East Germany through Reunification.” Journal of the Economics of Ageing. Available at: http://dx.doi.org/10.1016/j.jeoa.2014.09.001.

Waldron, Hillary. 2007. "Trends in Mortality Differentials and Life Expectancy for Male Social Security-Covered Workers, by Socioeconomic Status.” Social Security Bulletin 67(3): 128. 
_ 2013. "Mortality Differentials by Lifetime Earnings Decile: Implications for Evaluations of Proposed Social Security Law Changes.” Social Security Bulletin 73(1): 1-37.

Wilkins, Russell, Michael Tjepkema, Cameron Mustard, and Robert Choinière. 2008. “The Canadian Census Mortality Follow-up Study, 1991 through 2001.” Health Reports 19(3): 25-43.

Wolfson, Michael, Geoff Rowe, Jane F. Gentleman, and Monica Tomiak. 1993. "Career Earnings and Death: A Longitudinal Analysis of Older Canadian Men.” Journal of Gerontology 48(4): S167-S179. 
Table 1. Mortality Samples of the SIPP and HRS by Birth Decades

\begin{tabular}{|c|c|c|c|c|c|c|c|c|c|c|}
\hline \multicolumn{11}{|c|}{ SIPP } \\
\hline & \multicolumn{5}{|c|}{ Men } & \multicolumn{5}{|c|}{ Women } \\
\hline $\begin{array}{c}\text { Birth year } \\
\text { cohort }\end{array}$ & Total & $\begin{array}{c}\text { With nonzero } \\
\text { household } \\
\text { earnings }\end{array}$ & $\begin{array}{c}\text { Deaths up to } \\
2013 \text { (w/ } \\
\text { nonzero } \\
\text { household } \\
\text { earnings) }\end{array}$ & $\begin{array}{c}\text { Death } \\
\text { rate }\end{array}$ & $\begin{array}{c}\text { Social } \\
\text { Security } \\
\text { Benefits } \\
\text { Receipients }\end{array}$ & Total & $\begin{array}{c}\text { With nonzero } \\
\text { household } \\
\text { earnings }\end{array}$ & $\begin{array}{c}\text { Deaths up to } \\
2013 \text { (w/ } \\
\text { nonzero } \\
\text { household } \\
\text { earnings) }\end{array}$ & $\begin{array}{l}\text { Death } \\
\text { rate }\end{array}$ & $\begin{array}{c}\text { Social } \\
\text { Security } \\
\text { Benefits } \\
\text { Receipients }\end{array}$ \\
\hline 1910-1919 & 4,560 & 3,931 & 3,632 & $92 \%$ & 4,071 & 6,829 & 4,640 & 4,037 & $87 \%$ & 5,833 \\
\hline 1920-1929 & 10,767 & 8,193 & 5,388 & $66 \%$ & 8,455 & 13,869 & 9,508 & 4,986 & $52 \%$ & 10,662 \\
\hline 1930-1939 & 14,010 & 10,566 & 3,650 & $35 \%$ & 10,790 & 16,199 & 11,761 & 2,831 & $24 \%$ & 12,263 \\
\hline 1940-1949 & 21,055 & 15,846 & 2,114 & $13 \%$ & 13,896 & 23,136 & 17,451 & 1,618 & $9 \%$ & 16,122 \\
\hline $1950-1961 * *$ & 35,344 & 25,582 & 1,033 & $4 \%$ & 4,712 & 38,673 & 28,543 & 754 & $3 \%$ & 7,601 \\
\hline Total & 85,736 & 64,118 & 15,817 & $25 \%$ & 41,924 & 98,706 & 71,903 & 14,226 & $20 \%$ & 52,481 \\
\hline \multicolumn{11}{|c|}{ HRS } \\
\hline & \multicolumn{5}{|c|}{ Men } & \multicolumn{5}{|c|}{ Women } \\
\hline $\begin{array}{c}\text { Birth year } \\
\text { cohort }\end{array}$ & Total & $\begin{array}{l}\text { With nonzero } \\
\text { household } \\
\text { earnings*** }\end{array}$ & $\begin{array}{l}\text { Deaths up to } \\
2010\end{array}$ & $\begin{array}{l}\text { Death } \\
\text { rate }\end{array}$ & $\begin{array}{c}\text { Social } \\
\text { Security } \\
\text { Benefits } \\
\text { Receipients } \\
\end{array}$ & Total & $\begin{array}{l}\text { With nonzero } \\
\text { household } \\
\text { earnings*** }\end{array}$ & $\begin{array}{l}\text { Deaths up to } \\
2010\end{array}$ & $\begin{array}{l}\text { Death } \\
\text { rate }\end{array}$ & $\begin{array}{c}\text { Social } \\
\text { Security } \\
\text { Benefits } \\
\text { Receipients } \\
\end{array}$ \\
\hline 1910-1919 & 1,621 & 263 & 1,474 & $91 \%$ & 1,588 & 2,399 & 652 & 2,016 & $84 \%$ & 2,347 \\
\hline 1920-1929 & 2,817 & 1,156 & 1,688 & $60 \%$ & 2,763 & 3,194 & 1,191 & 1,546 & $48 \%$ & 3,142 \\
\hline 1930-1939 & 4,312 & 2,666 & 1,511 & $35 \%$ & 3,633 & 4,737 & 2,773 & 1,161 & $25 \%$ & 4,247 \\
\hline 1940-1949 & 2,998 & 1,768 & 432 & $14 \%$ & 1,778 & 4,124 & 2,527 & 442 & $11 \%$ & 2,929 \\
\hline $1950-1957 * *$ & 1,554 & 608 & 71 & $5 \%$ & 258 & 2,311 & 976 & 63 & $3 \%$ & 607 \\
\hline Total & 13,302 & 6,461 & 5,176 & $39 \%$ & 10,020 & 16,765 & 8,119 & 5,228 & $31 \%$ & 13,272 \\
\hline
\end{tabular}

** SIPP earnings records were available up to 2011, which allowed us to use respondents born up to 1961; HRS earnings records were only available up to 2007, limiting analysis to birth years up to 1957.

***Only includes non-zero household earnings where neither spouse had missing quarterly flag patterns and earnings at the maximum taxable amount up to 1977. 
Table 2. Mortality Regressions using all SES indicators, SIPP

\begin{tabular}{|c|c|c|c|c|}
\hline \multirow{3}{*}{$\begin{array}{l} \\
\text { Intercept }\end{array}$} & \multirow{2}{*}{\multicolumn{2}{|c|}{$\begin{array}{c}\text { Men } \\
(1) \\
\end{array}$}} & \multirow{2}{*}{\multicolumn{2}{|c|}{$\begin{array}{c}\text { Women } \\
(2) \\
\end{array}$}} \\
\hline & & & & \\
\hline & -9.2690 & $* * *$ & -10.8681 & $* * *$ \\
\hline Age & 0.0877 & $* * *$ & 0.0982 & $* * *$ \\
\hline Birth year (- 1900) & -0.0068 & $* * *$ & 0.0034 & $*$ \\
\hline \multicolumn{5}{|c|}{ SES Indicators } \\
\hline Household Earnings (\$1000's) & -0.0033 & $* * *$ & -0.0029 & $* * *$ \\
\hline Relative Education & -0.0908 & $* *$ & -0.0909 & $*$ \\
\hline Household Wealth (\$1000's) & -0.0003 & $* * *$ & -0.0001 & $*$ \\
\hline \multicolumn{5}{|c|}{ Race / ethnicity } \\
\hline Black (yes=1) & -0.0096 & & -0.0196 & \\
\hline White, Hispanic, Other & \multicolumn{4}{|c|}{ Reference Group } \\
\hline \multicolumn{5}{|c|}{ Marital Status } \\
\hline Never (yes=1) & 0.3522 & $* * *$ & 0.2607 & $* * *$ \\
\hline Separated / Divorced (yes=1) & 0.3090 & $* * *$ & 0.1301 & $* * *$ \\
\hline Married / Widowed (yes=1) & \multicolumn{4}{|c|}{ Reference Group } \\
\hline \multicolumn{5}{|c|}{ Self-Reported Health (1st Wave) } \\
\hline 1 (Excellent) & -0.4266 & $* * *$ & -0.4549 & $* * *$ \\
\hline 2 (Very Good) & -0.3035 & $* * *$ & -0.2849 & $* * *$ \\
\hline 3 (Good) & \multicolumn{4}{|c|}{ Reference Group } \\
\hline 4 (Fair) & 0.3447 & $* * *$ & 0.3736 & $* * *$ \\
\hline 5 (Poor) & 0.8074 & $* * *$ & 0.8213 & $* * *$ \\
\hline First-year in Survey (yes = 1) & -2.3709 & $* * *$ & -2.9317 & $* * *$ \\
\hline No. of observations & 640,209 & & 753,980 & \\
\hline Psuedo R-square & 0.030 & & 0.026 & \\
\hline $\begin{array}{l}* * *: p<0.001 \\
* *: p<0.01 \\
*: p<0.1\end{array}$ & & & & \\
\hline
\end{tabular}


Table 3. Mortality Regressions using Alternative SES Indicators with Birth year Interaction, SIPP

\begin{tabular}{|c|c|c|c|c|c|c|}
\hline & \multicolumn{3}{|c|}{ Men } & \multicolumn{3}{|c|}{ Women } \\
\hline & $\begin{array}{c}\text { Equivalized } \\
\text { Midcareer } \\
\text { Earnings } \\
\text { (\$1,000's) }\end{array}$ & $\begin{array}{c}\text { Relative } \\
\text { Education }\end{array}$ & $\begin{array}{r}\text { Total Household } \\
\text { Wealth }(\$ 1,000 \text { 's) }\end{array}$ & $\begin{array}{c}\text { Equivalized } \\
\text { Midcareer } \\
\text { Earnings } \\
\text { (\$1,000's) }\end{array}$ & $\begin{array}{c}\text { Relative } \\
\text { Education }\end{array}$ & $\begin{array}{r}\text { Total Household } \\
\text { Wealth (\$1,000's) }\end{array}$ \\
\hline & $(1)$ & $(2)$ & $(3)$ & $(4)$ & $(5)$ & $(6)$ \\
\hline Intercept & $-8.5095 * * *$ & $-8.7127 * * *$ & $-9.14560 * * *$ & $-10.1181 * * *$ & $-10.4474 * * *$ & $-10.6135 * * *$ \\
\hline Age & $0.0795 * * *$ & $0.0795 * * *$ & $0.08400 * * *$ & $0.0929 * * *$ & $0.0929 * * *$ & $0.0960 * * *$ \\
\hline Birth year (- 1900) & 0.0009 & $0.0103 * * *$ & $-0.00874 * * *$ & $0.0073 * * *$ & $0.0204 * * *$ & $-0.0039 * *$ \\
\hline \multicolumn{7}{|c|}{ SES } \\
\hline Household Earnings & $0.0072 * * *$ & $-0.0052 * * *$ & & $0.0063 * * *$ & $-0.0048 * * *$ & \\
\hline Earnings $x$ Birth year Interaction & $-0.0004 * * *$ & & & $-0.0004 * * *$ & & \\
\hline Relative Education & $-0.4223 * * *$ & $0.3994 * * *$ & & $-0.4234 * * *$ & $0.3177 * * *$ & \\
\hline Education x Birth year Interaction & & $-0.0310 * * *$ & & & $-0.0290 * * *$ & \\
\hline Wealth & & & $0.00050 * * *$ & & & $-0.0003 * * *$ \\
\hline Wealth x Birth year Interaction & & & $-0.00004 * * *$ & & & 0.0000 \\
\hline \multicolumn{7}{|c|}{ Race / ethnicity } \\
\hline Black (yes=1) & $0.1123 * * *$ & $0.1148 * * *$ & $0.15800 * * *$ & $0.1115 * * *$ & $0.1174 * * *$ & $0.1558 * * *$ \\
\hline White, Hispanic, Other & & Reference Group & & & Reference Group & \\
\hline \multicolumn{7}{|c|}{ Marital Status } \\
\hline Never (yes=1) & $0.3138 * * *$ & $0.3659 * * *$ & $0.43380 * * *$ & $0.1933 * * *$ & $0.2508 * * *$ & $0.2239 * * *$ \\
\hline Separated / Divorced (yes=1) & $0.3436 * * *$ & $0.3736 * * *$ & $0.35620 * * *$ & $0.0998 * * *$ & 0.1543 *** & $0.2142 * * *$ \\
\hline Married / Widowed (yes=1) & & Reference Group & & & Reference Group & \\
\hline First-year in Survey (yes = 1) & $-0.7242 * * *$ & $-0.7230 * * *$ & $-2.27980 * * *$ & $-0.9094 * * *$ & $-0.9128 * * *$ & $-2.7192 * * *$ \\
\hline No. of observations & 699,004 & 699,004 & 685,154 & 817,462 & 817,462 & 835,345 \\
\hline Psuedo R-square & 0.027 & 0.026 & 0.026 & 0.023 & 0.023 & 0.025 \\
\hline
\end{tabular}

$* * *: p<0.001$

$* *: p<0.01$

$*: p<0.1$ 
Table 4a. Mortality Regressions Using Alternative SES Indicators, Health and Retirement Study

\begin{tabular}{|c|c|c|c|c|}
\hline & $\begin{array}{c}\text { Actual Equivalized } \\
\text { Midcareer } \\
\text { Earnings } \\
(\$ 1,000 ' s) \\
\end{array}$ & $\begin{array}{l}\text { Predicted } \\
\text { Equivalized } \\
\text { Midcareer } \\
\text { Earnings } \\
\text { (\$1,000's) }\end{array}$ & $\begin{array}{l}\text { Relative } \\
\text { Education }\end{array}$ & $\begin{array}{l}\text { Total Household } \\
\text { Wealth (\$1,000's) }\end{array}$ \\
\hline & $(1)$ & $(2)$ & $(3)$ & $(4)$ \\
\hline \multicolumn{5}{|c|}{ MEN } \\
\hline Intercept & $-9.8046 * * *$ & $-9.4555 * * *$ & $-9.2126 * * *$ & $-9.1992 * * *$ \\
\hline Age & $0.0920 * * *$ & $0.0843 * * *$ & $0.0838 * * *$ & $0.0845 * * *$ \\
\hline Birth year (- 1900) & -0.0038 & $0.0155 * *$ & -0.0014 & $-0.0110 * * *$ \\
\hline SES & -0.0028 & $0.0060 *$ & 0.1139 & $0.1970 *$ \\
\hline SES x Birth year & $-0.0001 *$ & $-0.0006 * * *$ & $-0.0145 * *$ & $-0.0200 * * *$ \\
\hline \multicolumn{5}{|c|}{ Race / ethnicity } \\
\hline Black (yes=1) & $0.1871 * * *$ & $0.1116 * *$ & $0.1809 * * *$ & $0.1730 * * *$ \\
\hline White, Hispanic, Other & Reference Group & & & \\
\hline \multicolumn{5}{|c|}{ Marital Status } \\
\hline Never (yes=1) & $0.2468 *$ & 0.0692 & $0.3166 * * *$ & $0.3111 * * *$ \\
\hline Separated / Divorced & $0.4068 * * *$ & $0.2523 * * *$ & $0.3560 * * *$ & $0.3372 * * *$ \\
\hline Married / Widowed & Reference Group & & & \\
\hline Ever Disabled & $0.7399 * * *$ & $0.5986 * * *$ & $0.7560 * * *$ & $0.7602 * * *$ \\
\hline First-year in Survey & $-1.6690 * * *$ & $-1.6360 * * *$ & $-1.6463 * * *$ & $-1.6255 * * *$ \\
\hline No. of observations & 109,602 & 160,366 & 161,893 & 162,033 \\
\hline Psuedo R-square & 0.027 & 0.029 & 0.029 & 0.029 \\
\hline
\end{tabular}

\begin{tabular}{|c|c|c|c|c|}
\hline \multicolumn{5}{|c|}{ WOMEN } \\
\hline Intercept & $-11.7080 * * *$ & $-11.0120 * * *$ & $-11.1740 * * *$ & $-10.9370 * * *$ \\
\hline Age & $0.1043 * * *$ & $0.0976 * * *$ & $0.0984 * * *$ & $0.0987 * * *$ \\
\hline Birth year (- 1900) & $0.0166 * *$ & $0.0198 * * *$ & $0.0197 * * *$ & 0.0002 \\
\hline SES & $0.0061 *$ & 0.0033 & $0.3241 * *$ & $0.2950 * *$ \\
\hline SES x Birth year Interaction & $-0.0004 * * *$ & $-0.0005 * * *$ & $-0.0257 * * *$ & $-0.0200 * * *$ \\
\hline \multicolumn{5}{|l|}{ Race / ethnicity } \\
\hline Black & 0.0823 & $0.1076 * *$ & $0.1876 * * *$ & $0.1534 * * *$ \\
\hline White, Hispanic, Other & Reference Group & & & \\
\hline \multicolumn{5}{|l|}{ Marital Status } \\
\hline Never & 0.1333 & $0.1297 *$ & $0.2171 * *$ & $0.1825 *$ \\
\hline Separated / Divorced & 0.0630 & 0.0094 & $0.1519 * *$ & $0.1018 *$ \\
\hline Married / Widowed & Reference Group & & & \\
\hline Ever Disabled & $0.7836 * * *$ & $0.6502 * * *$ & $0.7520 * * *$ & $0.7633 * * *$ \\
\hline First-year in Survey & $-2.1134 * * *$ & $-2.2541 * * *$ & $-2.2687 * * *$ & $-2.2250 * * *$ \\
\hline No. of observations & 137,432 & 213,772 & 215,909 & 216,086 \\
\hline Psuedo R-square & 0.024 & 0.028 & 0.028 & 0.028 \\
\hline
\end{tabular}


Table 4b. Mortality Regressions Using Occupation as SES Indicator with Birth year Interaction, Health and Retirement Study

\begin{tabular}{|c|c|c|c|c|}
\hline & \multicolumn{2}{|c|}{ Men } & \multicolumn{2}{|c|}{ Women } \\
\hline & $\begin{array}{l}\text { No Birth year } \\
\text { Interaction }\end{array}$ & $\begin{array}{l}\text { With Birth year } \\
\text { Interaction }\end{array}$ & $\begin{array}{l}\text { No Birth year } \\
\text { Interaction }\end{array}$ & $\begin{array}{c}\text { With Birth year } \\
\text { Interaction }\end{array}$ \\
\hline & $(1)$ & $(2)$ & (3) & $(4)$ \\
\hline Intercept & $-9.6543 * * *$ & $-9.6919 * * *$ & $-11.4874 * * *$ & $-10.9108 * * *$ \\
\hline Age & $0.0882 * * *$ & $0.0883 * * *$ & $0.1039 * * *$ & $0.1042 * * *$ \\
\hline Birth year (- 1900) & $-0.0127 * * *$ & $-0.0114 *$ & -0.0026 & $-0.0249 * * *$ \\
\hline \multicolumn{5}{|c|}{ Occupations } \\
\hline Professional/Technical & -0.0712 & 0.2085 & -0.0569 & $-0.3648 *$ \\
\hline Prof x Birth year Interaction & & $-0.0106 *$ & & 0.0107 \\
\hline Sales Workers & 0.0880 & 0.0341 & 0.0426 & $-0.6099 *$ \\
\hline Sales x Birth year & & 0.0019 & & $0.0241 * *$ \\
\hline Clerical Workers & $0.2710 * * *$ & $0.4205 *$ & -0.0217 & $-0.5499 * *$ \\
\hline Clerical x Birth year & & -0.0056 & & $0.0194 * *$ \\
\hline Craftsmen/Foremen & $0.1516 * *$ & 0.2209 & 0.0280 & $-0.6740 *$ \\
\hline Craftsmen x Birth year & & -0.0026 & & $0.0260 *$ \\
\hline Operatives & $0.2294 * * *$ & $0.3228 *$ & $0.2712 * * *$ & -0.2989 \\
\hline Operative x Birth year & & -0.0035 & & $0.0210 * *$ \\
\hline Laborers/Farm Foremen & $0.1339 *$ & -0.0108 & 0.0551 & $-0.8527 *$ \\
\hline Laborer x Birth year & & 0.0054 & & $0.0328 *$ \\
\hline Service workers & $0.2528 * * *$ & -0.0831 & $0.1615 *$ & $-0.9106 * * *$ \\
\hline Service x Birth year & & 0.0113 & & $0.0393 * * *$ \\
\hline Member of Armed Forces & $0.3585 * *$ & -0.0298 & -0.0498 & 2.1729 \\
\hline AF x Birth year Interaction & & 0.0110 & & -0.0635 \\
\hline Mangerial/Officials & Refere & Group & Refere & Group \\
\hline \multicolumn{5}{|l|}{ Race / ethnicity } \\
\hline Black (yes=1) & $0.1702 * * *$ & $0.1712 * * *$ & $0.1132 *$ & $0.1330 * *$ \\
\hline White, Hispanic, Other & \multicolumn{2}{|c|}{ Reference Group } & \multicolumn{2}{|c|}{ Reference Group } \\
\hline \multicolumn{5}{|l|}{ Marital Status } \\
\hline Never Married & $0.3133 * * *$ & $0.3135 * * *$ & $0.2765 * *$ & $0.2585 * *$ \\
\hline Separated / Divorced & $0.3408 * * *$ & $0.3369 * * *$ & $0.2276 * * *$ & $0.2269 * * *$ \\
\hline Married / Widowed & \multicolumn{2}{|c|}{ Reference Group } & \multicolumn{2}{|c|}{ Reference Group } \\
\hline Ever Disabled & $0.7958 * * *$ & $0.7923 * * *$ & $0.8514 * * *$ & $0.8228 * * *$ \\
\hline First-year in Survey & $-1.6168 * * *$ & $-1.6167 * * *$ & $-2.0268 * * *$ & $-2.0262 * * *$ \\
\hline No. of observations & 150,369 & 150,369 & 170,921 & 170,921 \\
\hline Psuedo R-square & 0.029 & 0.029 & 0.024 & 0.024 \\
\hline
\end{tabular}

$* * *: p<0.001 ; * *: p<0.01 ; *: p<0.1$ 
Table 5. Distribution of Annual and Lifetime OASDI Benefits by Equivalized Earnings Deciles

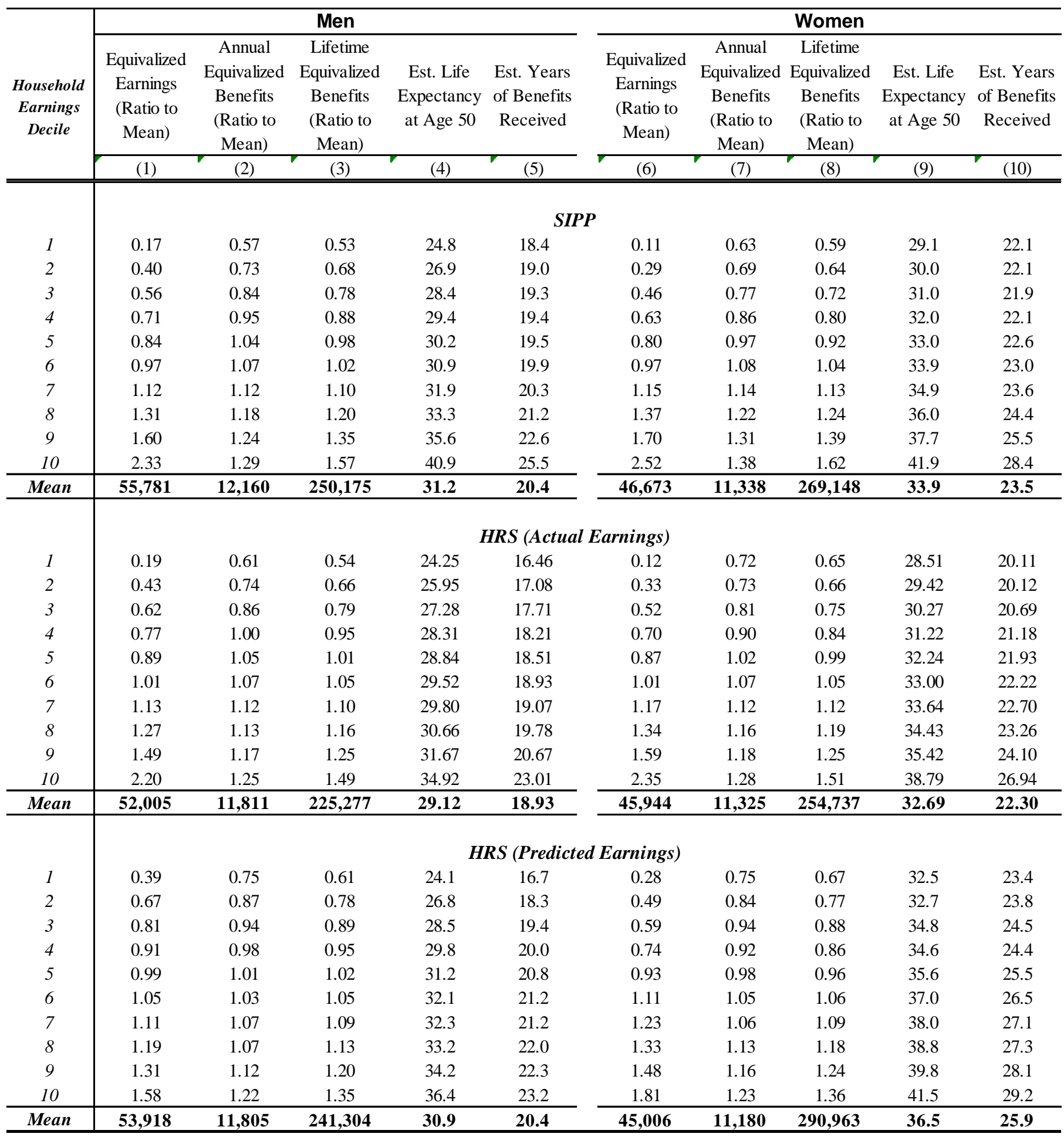

Source: Authors' calculations as described in text. Equivalized earnings and benefits use the combined total for couples divided by the square root of 2 . 
Table 6. Estimated Life Expectancies and Expected Years of Benefits by Equivalized Household Earnings Deciles, 1920 and 1940 Birth years

\begin{tabular}{|c|c|c|c|c|c|c|c|c|c|c|c|c|}
\hline \multirow{3}{*}{$\begin{array}{l}\text { Equivalized } \\
\text { household } \\
\text { earnings } \\
\text { decile }\end{array}$} & \multicolumn{6}{|c|}{ Men } & \multicolumn{6}{|c|}{ Women } \\
\hline & \multicolumn{2}{|c|}{$\begin{array}{c}\text { Life Expectancy } \\
\text { at age } 50\end{array}$} & \multicolumn{2}{|c|}{$\begin{array}{c}\text { Expected Years of } \\
\text { Benefits }\end{array}$} & \multicolumn{2}{|c|}{$\begin{array}{c}\text { Lifetime } \\
\text { Equivalized } \\
\text { Benefits (ratio to } \\
1920 \text { mean) }\end{array}$} & \multicolumn{2}{|c|}{$\begin{array}{l}\text { Life Expectancy } \\
\text { at age } 50\end{array}$} & \multicolumn{2}{|c|}{$\begin{array}{c}\text { Expected Years of } \\
\text { Benefits }\end{array}$} & \multicolumn{2}{|c|}{$\begin{array}{c}\text { Lifetime } \\
\text { Equivalized } \\
\text { Benefits (ratio to } \\
1920 \text { mean) }\end{array}$} \\
\hline & $\begin{array}{c}1920 \\
(1) \\
\end{array}$ & $\begin{array}{c}1940 \\
(2) \\
\end{array}$ & $\begin{array}{c}1920 \\
(3) \\
\end{array}$ & $\begin{array}{c}1940 \\
(4) \\
\end{array}$ & $\begin{array}{c}1920 \\
(5) \\
\end{array}$ & $\begin{array}{c}1940 \\
(6) \\
\end{array}$ & $\begin{array}{c}1920 \\
(7) \\
\end{array}$ & $\begin{array}{c}1940 \\
(8) \\
\end{array}$ & $\begin{array}{c}1920 \\
(9) \\
\end{array}$ & $\begin{array}{r}1940 \\
(10) \\
\end{array}$ & $\begin{array}{r}1920 \\
(11) \\
\end{array}$ & $\begin{array}{l}1940 \\
(12) \\
\end{array}$ \\
\hline & \multicolumn{12}{|c|}{ SIPP } \\
\hline 1 & 24.0 & 24.6 & 17.8 & 18.4 & 0.61 & 0.63 & 30.2 & 29.2 & 22.8 & 21.9 & 0.66 & 0.63 \\
\hline 2 & 24.7 & 26.5 & 17.5 & 19.0 & 0.74 & 0.80 & 30.4 & 30.1 & 22.3 & 22.0 & 0.71 & 0.70 \\
\hline 3 & 25.2 & 27.8 & 17.3 & 19.5 & 0.84 & 0.94 & 30.7 & 30.9 & 21.7 & 22.0 & 0.77 & 0.78 \\
\hline 4 & 25.7 & 28.9 & 17.1 & 19.9 & 0.93 & 1.08 & 31.0 & 31.9 & 21.5 & 22.3 & 0.85 & 0.88 \\
\hline 5 & 25.9 & 29.9 & 17.1 & 20.4 & 1.02 & 1.21 & 31.4 & 32.8 & 21.5 & 22.8 & 0.95 & 1.00 \\
\hline 6 & 26.2 & 30.8 & 17.1 & 21.0 & 1.05 & 1.28 & 31.7 & 33.7 & 21.5 & 23.3 & 1.06 & 1.15 \\
\hline 7 & 26.5 & 31.8 & 17.2 & 21.7 & 1.11 & 1.39 & 31.9 & 34.6 & 21.7 & 24.0 & 1.12 & 1.25 \\
\hline 8 & 26.8 & 33.1 & 17.4 & 22.6 & 1.17 & 1.53 & 32.3 & 35.7 & 21.8 & 24.9 & 1.21 & 1.38 \\
\hline 9 & 27.5 & 35.0 & 17.7 & 24.1 & 1.26 & 1.71 & 32.7 & 37.2 & 22.0 & 26.0 & 1.31 & 1.55 \\
\hline 10 & 28.3 & 38.7 & 18.1 & 26.6 & 1.33 & 1.96 & 33.7 & 40.3 & 22.7 & 28.4 & 1.42 & 1.78 \\
\hline \multirow[t]{2}{*}{ Mean } & 26.1 & 30.7 & 17.4 & 21.2 & \multicolumn{2}{|c|}{211,454} & 31.6 & 33.6 & 21.9 & 23.7 & \multicolumn{2}{|c|}{247,667} \\
\hline & \multicolumn{12}{|c|}{ HRS (Actual Earnings) } \\
\hline 1 & 23.7 & 24.4 & 16.0 & 16.7 & 0.55 & 0.57 & 29.9 & 27.6 & 21.2 & 19.1 & 0.70 & 0.63 \\
\hline 2 & 25.1 & 26.2 & 16.5 & 17.4 & 0.67 & 0.71 & 30.6 & 29.0 & 21.1 & 19.6 & 0.71 & 0.66 \\
\hline 3 & 26.3 & 27.7 & 17.0 & 18.1 & 0.80 & 0.85 & 31.0 & 30.0 & 21.3 & 20.4 & 0.79 & 0.76 \\
\hline 4 & 27.4 & 29.0 & 17.6 & 18.9 & 0.96 & 1.04 & 31.5 & 31.1 & 21.4 & 21.1 & 0.88 & 0.86 \\
\hline 5 & 27.9 & 29.6 & 17.8 & 19.3 & 1.02 & 1.11 & 32.1 & 32.3 & 21.8 & 22.0 & 1.02 & 1.03 \\
\hline 6 & 28.4 & 30.3 & 18.1 & 19.8 & 1.06 & 1.16 & 32.5 & 33.2 & 21.8 & 22.5 & 1.07 & 1.10 \\
\hline 7 & 28.7 & 30.8 & 18.3 & 20.1 & 1.11 & 1.22 & 32.7 & 34.0 & 22.0 & 23.1 & 1.12 & 1.18 \\
\hline 8 & 29.2 & 31.5 & 18.7 & 20.7 & 1.16 & 1.28 & 33.0 & 34.8 & 22.1 & 23.7 & 1.17 & 1.26 \\
\hline 9 & 29.8 & 32.4 & 19.3 & 21.5 & 1.23 & 1.38 & 33.3 & 36.0 & 22.3 & 24.7 & 1.20 & 1.33 \\
\hline 10 & 32.1 & 35.4 & 20.9 & 23.8 & 1.42 & 1.63 & 34.3 & 38.9 & 23.2 & 27.4 & 1.35 & 1.60 \\
\hline Mean & 27.8 & 29.7 & 18.0 & 19.6 & \multicolumn{2}{|c|}{214,162} & 32.1 & 32.7 & 21.8 & 22.3 & \multicolumn{2}{|c|}{246,820} \\
\hline
\end{tabular}


Figure 1. Male and Female Career Earnings by Birth Year 1910-1965, Thousands of 2005 Dollars

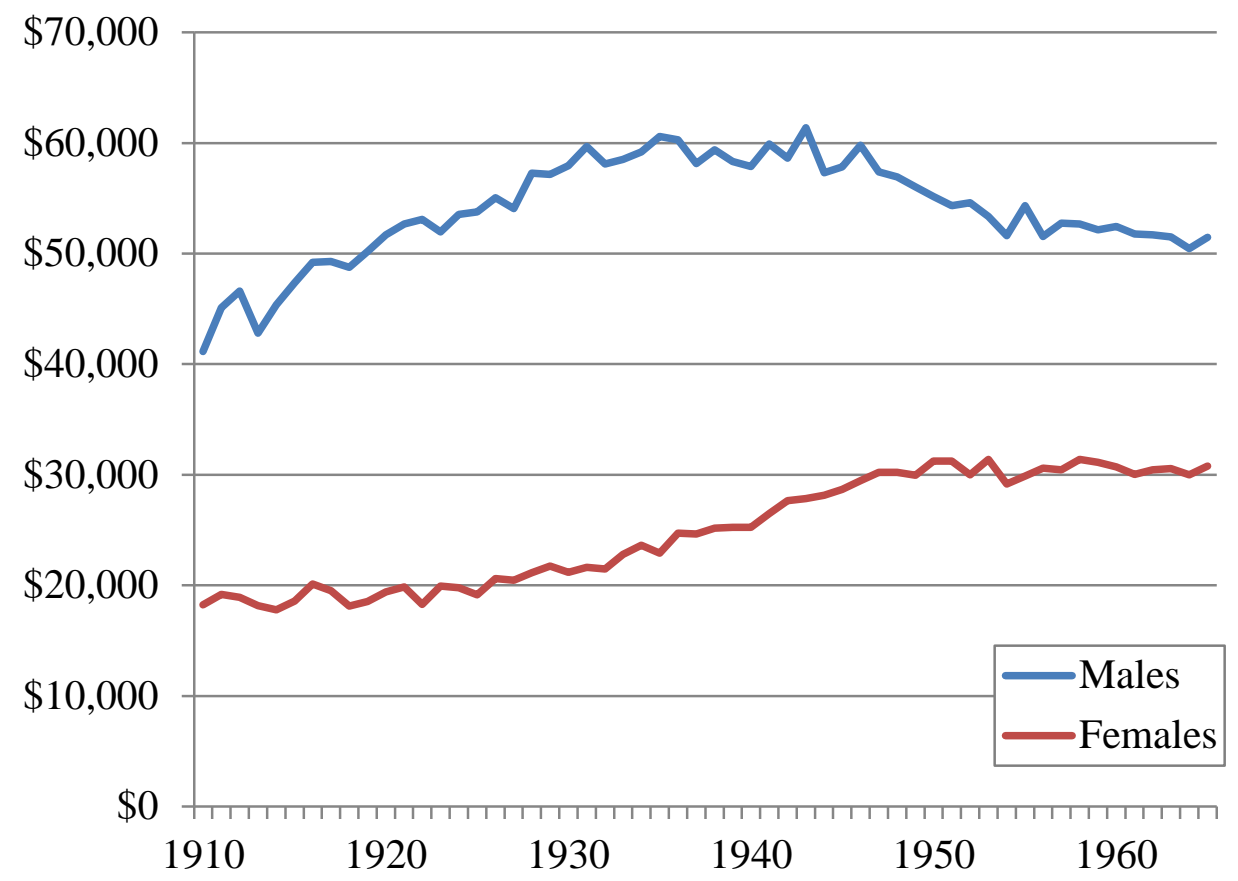

Source: Authors' calculations as explained in text. 
Figure 2. Distribution of Annual and Lifetime OASDI Benefits by Equivalized Earnings Deciles
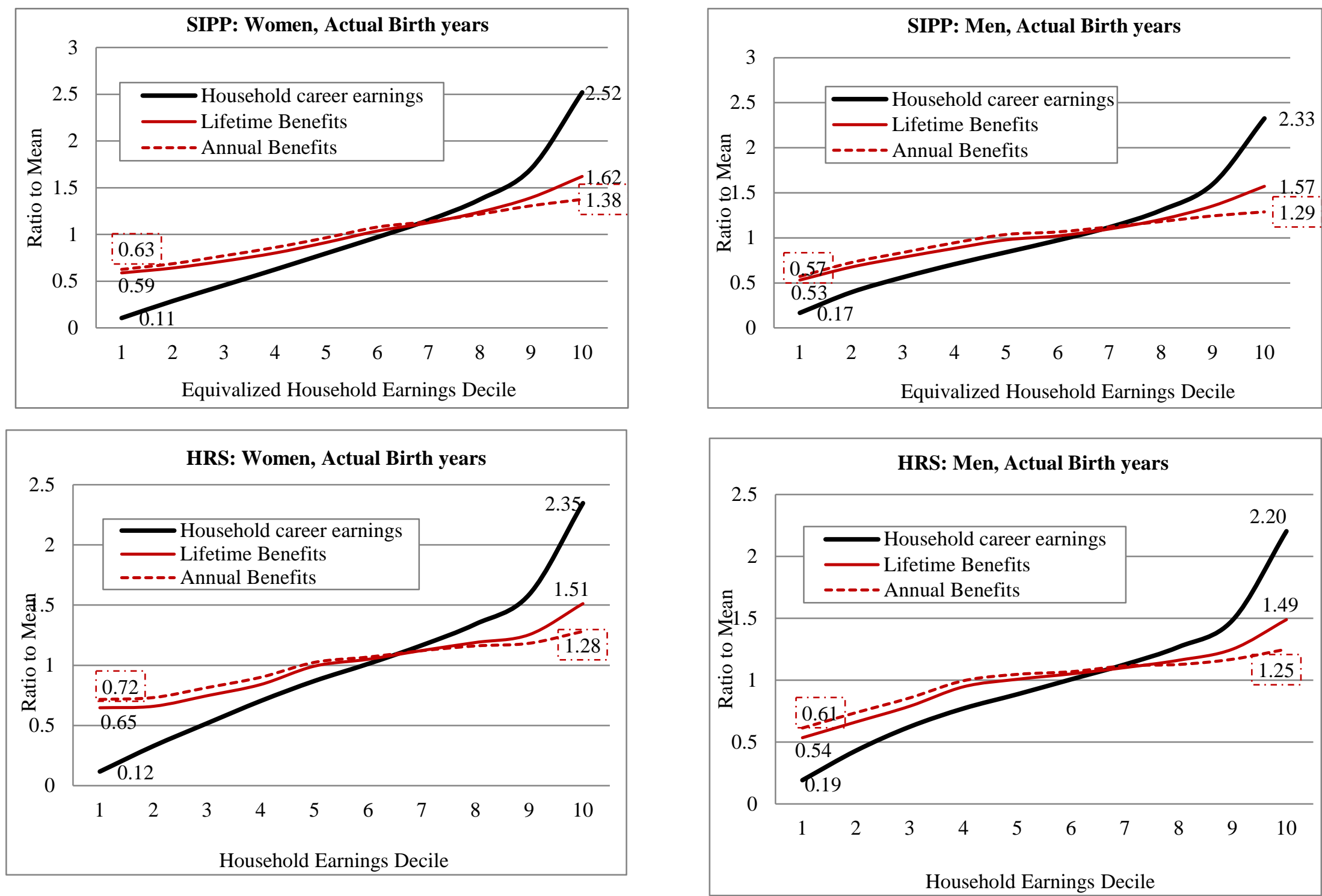

Source: Distribution of Annual and Lifetime OASDI Benefits by Equivalized Earnings Deciles. 
Figure 3. Distribution of Lifetime OASDI Benefits, 1920 and 1940 Birth Cohorts
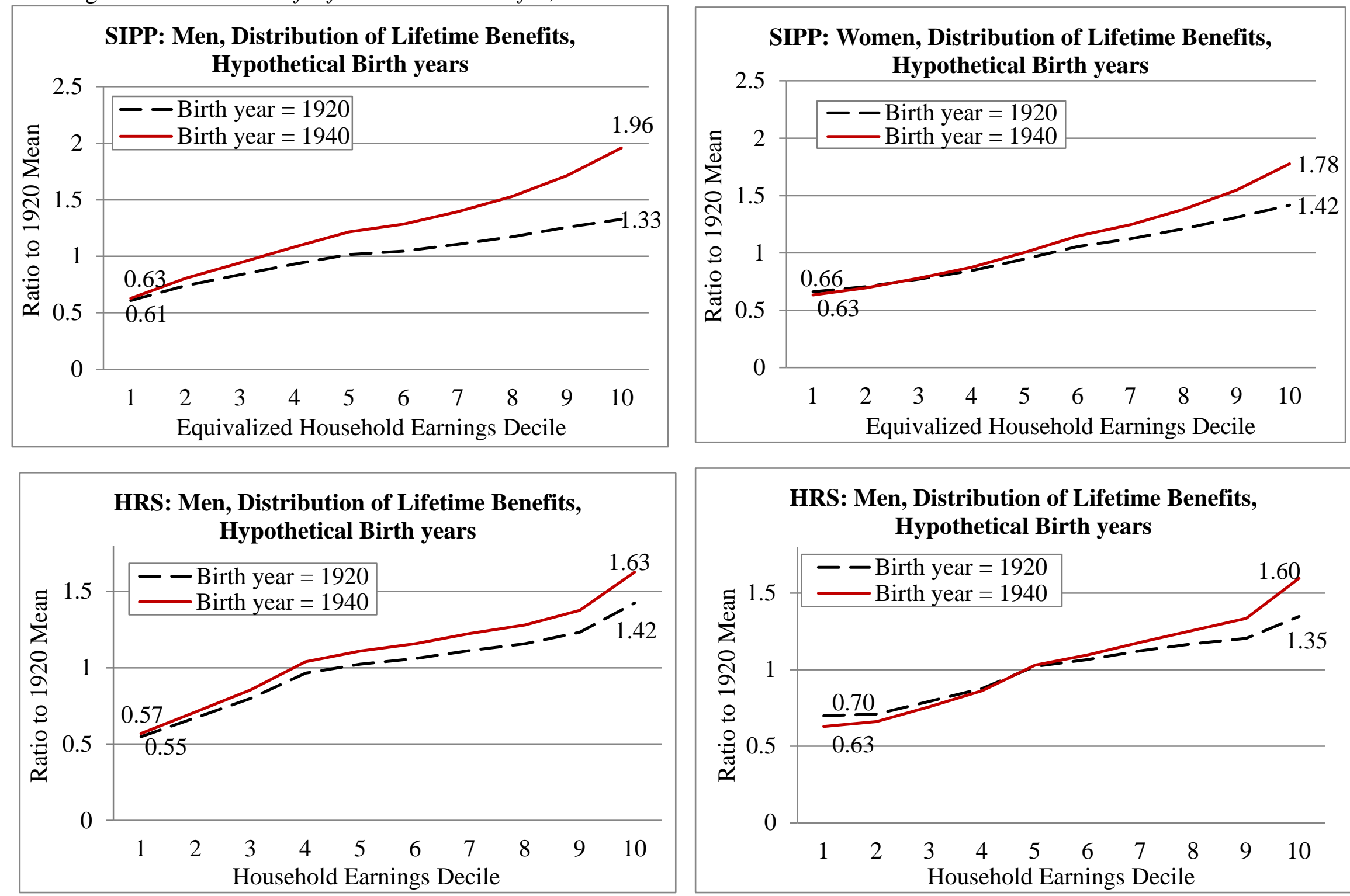

Source: Estimated Life Expectancies and Expected Years of Benefits by Equivalized Household Earnings Deciles, 1920 and 1940 Birth years. 
Table A1. Equivalized Midcareer Earnings (in 2005 \$1000's) Predictions, Health and Retirement Survey

\begin{tabular}{|c|c|c|c|c|}
\hline \multirow[b]{3}{*}{ Intercept } & \multicolumn{2}{|c|}{ Men } & \multicolumn{2}{|c|}{ Women } \\
\hline & (1) & (2) & (1) & (2) \\
\hline & $48.197 * * *$ & $24.723 * * *$ & $25.848 * * *$ & $2.463 *$ \\
\hline Relative Education & $21.770 * * *$ & $28.537 * * *$ & $12.335 * * *$ & $17.250 * * *$ \\
\hline Relative Education Spline & $3.840 * *$ & $5.167 * * *$ & $1.649 * *$ & $3.412 * * *$ \\
\hline Household Wealth (\$1,000's) & $0.016 * * *$ & $0.017 * * *$ & $0.006 * * *$ & $0.006 * * *$ \\
\hline \multicolumn{5}{|c|}{ Longest Occupation } \\
\hline Professional specialty & $-11.443 * * *$ & & $-5.974 * * *$ & \\
\hline Sales & $-12.479 * * *$ & & $-16.650 * * *$ & \\
\hline Clerical/admin support & $-22.132 * * *$ & & $-11.291 * * *$ & \\
\hline Craftsmen / Foremen & $-16.745 * * *$ & & $-9.497 * * *$ & \\
\hline Operatives & $-18.103 * * *$ & & $-10.936 * * *$ & \\
\hline Laborers / farm foremen & $-29.634 * * *$ & & $-16.630 * * *$ & \\
\hline Service workers & $-25.361 * * *$ & & $-19.721 * * *$ & \\
\hline Member of Armed Forces & $-27.951 * * *$ & & -1.066 & \\
\hline Manegerial & Reference Group & & Reference Group & \\
\hline Birth year $(-1900)$ & $0.125 *$ & $0.153 * *$ & $-0.103 * * *$ & $0.040 *$ \\
\hline \multicolumn{5}{|c|}{ Race / ethnicity } \\
\hline Black (yes=1) & $-7.801 * * *$ & $-10.538 * * *$ & $2.970 * * *$ & $1.438 *$ \\
\hline Hispanic, non-white (yes=1) & $-8.720 * * *$ & $-9.976 * * *$ & -0.372 & -0.840 \\
\hline Other (yes=1) & $-16.155 * * *$ & $-16.304 * * *$ & 2.708 & 1.638 \\
\hline White (yes=1) & \multicolumn{2}{|c|}{ Reference Group } & \multicolumn{2}{|c|}{ Reference Group } \\
\hline \multicolumn{5}{|c|}{ Marital Status } \\
\hline Never (yes=1) & $-20.310 * * *$ & $-22.598 * * *$ & $10.026 * * *$ & $9.878 * * *$ \\
\hline Separated / Divorced (yes=1) & $-10.090 * * *$ & $-11.495 * * *$ & $3.166 * * *$ & $3.512 * * *$ \\
\hline Married / Widowed (yes=1) & \multicolumn{2}{|c|}{ Reference Group } & \multicolumn{2}{|c|}{ Reference Group } \\
\hline Ever Disabled (yes=1) & $-11.958 * * *$ & $-13.792 * * *$ & $-4.140 * * *$ & $-5.070 * * *$ \\
\hline No. of observations & 6,451 & 6,907 & 8,084 & 9,194 \\
\hline$R$-square & 0.240 & 0.215 & 0.216 & 0.139 \\
\hline
\end{tabular}




\section{RECENT WORKING PAPERS FROM THE CENTER FOR RETIREMENT RESEARCH AT BOSTON COLLEGE}

Slowed or Sidelined? The Effect of "Normal” Cognitive Decline on Job Performance Among the Elderly

Anek Belbase, Mashfiqur R. Khan, Alicia H. Munnell, and Anthony Webb, June 2015

Does Social Security Continue to Favor Couples?

Nadia S. Karamcheva, April Yanyuan Wu, and Alicia H. Munnell, June 2015

Sources of Increasing Differential Mortality Among the Aged by Socioeconomic Status Barry P. Bosworth, Gary Burtless, and Kan Zhang, June 2015

Do Retired Americans Annuitize Too Little? Trends in the Share of Annuitized Income Barry P. Bosworth, Gary Burtless, and Mattan Alalouf, June 2015

Impact of the Financial Crisis on Long-Term Growth

Barry P. Bosworth, June 2015

Post-War Trends in Labor Income in the Social Security Earnings Records Gary Burtless and Kan Zhang, June 2015

Improving Employees' Life and Disability Insurance Benefit Decisions: Results of an Employer Survey

Anek Belbase, Norma B. Coe, and Matthew S. Rutledge, June 2015

Overcoming Barriers to Life Insurance Coverage: A Behavioral Approach

Anek Belbase, Norma B. Coe, and April Yanyuan Wu, June 2015

How Do People Decide on Life Insurance and Long-Term Disability Insurance Coverage? Norma B. Coe and Anek Belbase, June 2015

What Do Subjective Assessments of Financial Well-Being Reflect?

Steven A. Sass, Anek Belbase, Thomas Cooperrider, and Jorge D. Ramos-Mercado, March 2015

The Impact of Leakages from 401(k)s and IRAs

Alicia H. Munnell and Anthony Webb, February 2015

Recruiting and Retaining High-Quality State and Local Workers: Do Pensions Matter? Alicia H. Munnell, Jean-Pierre Aubry, and Geoffrey T. Sanzenbacher, January 2015

All working papers are available on the Center for Retirement Research website (http://crr.bc.edu) and can be requested by e-mail (crr@bc.edu) or phone (617-552-1762). 